\title{
Chemical and Physical Characterization of Dromaius novaehollandiae (Emu) Eggs
}

\author{
Junko TAKeuchi* and Toshio NAgAShima
}

Faculty of Bio-industry, Tokyo University of Agriculture, 196 Yasaka, Abashiri, Hokkaido 099-2493, Japan

Received March 19, 2009; Accepted December 16, 2009

\begin{abstract}
Chemical and physical studies were conducted to investigate the potential use of emu (Dromaius novaehollandiae) eggs in the food industry. The proximate composition of the yolk and albumen of emu eggs was determined for the first time and revealed to be slightly different from hen eggs in lipid and water content. Though the increase in volume of emu whole eggs by whipping was smaller than that of hen eggs, the whip was more stable. However, freezing dramatically decreased the whipping capacity of emu whole eggs. The most significant difference found was when emu eggs were subjected to heat-induced coagulation; both the albumen and yolk of emu eggs had a softer texture compared to hen eggs. These characteristics are promising for processed food production, especially for softening products. A cake, for example, made with emu eggs was revealed to be softer than a cake made with hen eggs.
\end{abstract}

Keywords: egg, albumen, emu, food processing

\section{Introduction}

The emu (Dromaius novaehollandiae) is the world's second largest bird and is native to Australia. Since emus are able to live in severe climates such as northern Japan, interest in domesticated emu rearing has been growing. Though meat and oil are the primary products from farmed emus, their eggs are also an important farming product. Emus lay greenshelled eggs during winter that are about 10 times larger than hen eggs (Koga, 1969). An emu egg contains an almost equal volume of yolk and albumen, unlike most avian eggs whose volume of albumen is two times greater than that of the yolk (Koga, 1969, Sales et al., 1996). Emu eggs have been used as food material, although their physical properties have not been thoroughly clarified. The hen egg has unique properties (such as whipping, coagulation, and emulsification) in each of the fractions of whole egg, albumen, and yolk (Yang and Baldwin, 1995). How can these properties be reproduced in an emu egg? To expand the use of emu eggs within the food industry, it is necessary to understand their physical properties as well as proximate composition. Though the proximate composition of whole emu egg has been investigated, there are no reports about its yolk or albumen. The shells of emu eggs are often recycled for craft purposes. Thus, the egg components are often extracted through a small hole in the

*To whom correspondence should be addressed. E-mail: j3takeuc@bioindustry.nodai.ac.jp shell in order for the shell to remain intact. In addition, the emu yolk and albumen are both extremely viscous, making it difficult to completely isolate them. Thus, in the case of emu, the whole egg is the most common way it is used as food material. To maximize the value of the emu egg for industrial use, investigation of the properties of the whole egg is vital. If it has excellent whipping characteristics, as with the albumen of hen eggs, emu eggs will be utilized more strategically. In terms of primary processing, frozen eggs are preferable due to ease of storage and transportation, and changes in characteristics that occur as a result of freezing should be clarified for future application. We assume that the utilization of emu eggs will be easiest in local bakeries because they are generally small but consume eggs daily. Our characterization is therefore mainly aimed at emu eggs in light of their potential use in bakery products. The poultry industry often feeds colorants, such as corn, seaweed, and flower petals, to laying hens to give the yolk a more brilliant orange color (Angalet, 1976; Herber-McNeill, 1998). Since emu farming is less established, color comparisons are perhaps not important at this time. However, since the disappearance of the emu egg yolk's natural yellowness by processing is known to be considerable, we compared the color of boiled eggs and processed foods that use the eggs of emus and hens.

\section{Materials and Methods}

Proximate composition Emu eggs were obtained from 
Tokyo Nodai Bio-industry (Hokkaido, Japan). Hen eggs were purchased from local stores and used as controls. Yolk and albumen were separated by straining at the edge of the shell, and each was homogenized. Scissors were used to remove viscous albumen from the yolk in the case of emu eggs. The whole eggs were independently homogenized. These samples were used to determine proximate composition by standard procedures (Mext, 2005). Protein content $(\mathrm{N} \times 6.25)$ was determined by the micro-Kjeldahl method using Kjeltec 2200 (Foss, Hillerød, Denmark). Chloroform-methanol (2:1) extraction and the anthrone-sulfic acid method were used to determine lipid and carbohydrate content, respectively. Water content was determined by drying the sample on quartz sands at $100^{\circ} \mathrm{C}$ in a drying oven. Ash content was determined by incinerating samples at $550^{\circ} \mathrm{C}$ in a muffle furnace. All determinations were calculated as the average of triplicate values. Triplicate variation was small enough to ignore unless otherwise noted.

Whip preparation Foams were prepared by whipping $30 \mathrm{~mL}$ of egg sample in a homogenizing cup (AM-7, Nihonseiki, Tokyo, Japan) on ice for $5 \mathrm{~min}$ at 5,000 rpm to maximize the volume. The whipped sample was immediately transferred into a mess cylinder, and the volume was measured. The syneresis rate at room temperature was determined by periodically reading the regenerated fluid volume.

SDS-PAGE analysis A standard procedure was used to perform SDS-PAGE analysis (Laemmli, 1970). Samples were diluted 10 fold with PBS buffer $(140 \mathrm{mM} \mathrm{NaCl}, 2.7$ $\mathrm{mM} \mathrm{KCl}, 10 \mathrm{mM} \mathrm{Na}_{2} \mathrm{HPO}_{4}$ and $1.8 \mathrm{mM} \mathrm{KH}_{2} \mathrm{PO}_{4}, \mathrm{pH}$ 6.8). A $1.0-\mu 1$ diluted sample was mixed with Laemmli buffer, heatdenatured, and subjected to electrophoresis using a $12.5 \%$ polyacrylamide gel.

Rheological analysis A raw egg sample was homogenized and packaged in a plastic casing tube with a diameter of $3.2 \mathrm{~cm}$ and heated for $10 \mathrm{~min}$ in $92^{\circ} \mathrm{C}$ simmering water. The sample was then left in off-heat hot water for $15 \mathrm{~min}$. After cooling at room temperature, the casing was peeled off, and 2-cm thick slices were prepared. The slices were then analyzed by a rheometer (NRM-2010J-CW, Rheotech,
Tokyo, Japan) equipped with a spherical plunger of $1.0-\mathrm{cm}$ diameter at a test speed of $60 \mathrm{~mm} / \mathrm{min}$. Analysis was performed as described by Hamada and Inamasu (1983). Briefly, the force and the depth of dent when the plunger began to penetrate a sample were measured. Shearing energy was calculated as the area by the time penetration began. Cakes were also sliced $2 \mathrm{~cm}$ thick and analyzed as described above, but this time a flat head plunger of $1.0 \mathrm{~cm}^{2}$ surface area was used. Firmness was calculated as the force that was required to dent a cake to a depth of $5.0 \mathrm{~mm}$. A Rapid Visco Analyzer RVA-4 (Newport Scientific, Warriewood, Australia) was used to measure the viscosity of the raw egg while the temperature changed. The precise program is described in the legend of Fig. 3. Samples $(30 \mathrm{~g})$ were placed into a canister and stirred at $160 \mathrm{rpm}$. Data was analyzed on a computer using the software, Thermocline. The viscosity of the raw egg sample was measured using a vibration-type viscosity meter (SV-10, AND, Tokyo, Japan) at $20^{\circ} \mathrm{C}$.

Color measurement A Konica Minolta CR-400 Chroma Meter (Tokyo, Japan) with illuminant $\mathrm{D}_{65}$ was used to measure the color of the sliced boiled egg and cake.

Cake preparation Cake batter was prepared by first softening $100 \mathrm{~g}$ of butter, followed by the addition of $100 \mathrm{~g}$ of granulated sugar. The batter was thoroughly mixed, and a pre-whisked whole egg (100 g) was added. After blending the batter, $100 \mathrm{~g}$ of wheat flour was added through a sieve (20 mesh). The batter was gently blended and transferred to a cake mold $(9.0 \mathrm{~cm} \times 17.0 \mathrm{~cm} \times 9.0 \mathrm{~cm})$ and then baked for $10 \mathrm{~min}$ at $190^{\circ} \mathrm{C}$ followed by $25 \mathrm{~min}$ at $180^{\circ} \mathrm{C}$. The seed displacement method using clover seeds was used to determine the volume of the cake.

\section{Results and Discussion}

Proximate composition The basic composition of the eggs was determined to identify how emu eggs differ from hen eggs. The composition of a standard Japanese hen egg (Mext, 2005) was used as a reference for comparison since it was the most up-to-date. As shown in Table 1, emu egg yolk contained $28.2 \%$ lipid, which is less than the $33.5 \%$ of stan-

Table 1. Proximate composition of emu egg in comparison to hen egg (\% constituents).

\begin{tabular}{lcccccc}
\hline & \multicolumn{3}{c}{ Emu } & \multicolumn{3}{c}{ Hen* } \\
\hline & Whole & Albumen & Yolk & Whole & Albumen & Yolk \\
\hline Water & 71.8 & 89.1 & 55.0 & 76.1 & 88.4 & 48.2 \\
Protein & 12.9 & 8.9 & 14.9 & 12.3 & 10.5 & 16.5 \\
Lipid & 13.8 & 1.1 & 28.2 & 10.3 & Trace & 33.5 \\
Carbohydrate & 0.2 & 0.2 & 0.2 & 0.3 & 0.4 & 0.1 \\
Ash & 1.3 & 0.7 & 1.7 & 1.0 & 0.7 & 1.7 \\
\hline
\end{tabular}

* The values of hen egg are cited from the standard tables of food composition in Japan (Mext, 2005) 
dard hen egg. However, the total lipid content of whole emu egg, $13.8 \%$, was higher than that of whole hen egg $(10.3 \%$ in general), since emu eggs contain an almost equal volume of yolk and albumen as previously reported (Koga 1969), and is in contrast to hen eggs, where the volume of albumen is about two times greater than that of the yolk. The content of whole hen egg is thus considerably influenced by its albumen composition. Likewise, although hen yolk contained almost $7 \%$ less water than emu yolk, overall, the water content of whole hen egg was $76.1 \%$, which was more than the $71.8 \%$ of whole emu egg. Differences in carbohydrate and ash composition were small due to their low content. Our results of whole egg composition are generally consistent with the previous partial analysis (Sales et al., 1996), which described the water, lipid, and protein content of whole emu egg. The composition of yolk and albumen was measured for the first time in our study and the whole egg composition reasonably reflected the 1:1 ratio of albumen and yolk. There was an inevitable but slight contamination of yolk fraction into albumen and vise versa, because, as we describe later, the albumen of emu eggs is extremely viscous. The contamination was insignificant, however, and did not affect the result. The difficulty of separating the albumen and yolk was due to the high viscosity of the albumen. This difficulty has also been observed in ostrich eggs (Mineki et al., 2003), although the emu is evolutionally different from the ostrich. In whole egg preparation, the portion of emu egg that was disposed (shell and unremovable albumen) was $13 \%$ by weight, which was the same as with the hen egg.

Viscosity of raw eggs The viscosity of emu egg albumen, yolk, and whole egg fraction was examined and compared with that of hen eggs. As shown in Table 2, emu egg albumen was almost four times more viscous than hen egg albumen. The viscosity of hen egg albumen is largely ascribed to ovomucin, a glycoprotein whose structural denaturation decreases the viscosity of albumen (Robinson et al., 1972). There may therefore be a difference in the glycosylation pattern or protein sequence of ovomucin between the two species. Yolk viscosity differs significantly between the two species. The yolk of emu eggs was almost 10 times

Table 2. Apparent viscosity of raw egg ( $\mathrm{mPa})$.

\begin{tabular}{crcc} 
& Whole & Albumen & Yolk \\
\hline Emu & $25.7 \pm 1.0$ & $3.4 \pm 0.4$ & $3003^{*} \pm 6$ \\
Hen & $4.3 \pm 0.1$ & $0.9 \pm 0.3$ & $330.3 \pm 3.5$ \\
\hline
\end{tabular}

Values are expressed as mean $\pm \mathrm{SD}(\mathrm{n}=3)$.

* Decimal value was not readable because the viscosity value was reported only in $\mathrm{Pa}$ due to its high viscosity. more viscous than the yolk of hen eggs. This result suggests differences in protein and lipid composition, most probably in low-density lipoproteins (LDL). LDL is the major component of yolk and causes the yolk to become denatured when it is frozen. Denaturation by freezing occurs more severely in emu egg yolk (data not shown), which implies a structural difference from hen egg yolk in LDL. As a whole egg, emu eggs showed nearly 6 times higher viscosity than hen eggs.

Whipping and syneresis properties We next compared the foaming property of eggs. Whole egg and albumen of each type of egg were whipped and their volume change was measured (Table 3). Generally, the volume of the whole emu egg increased from 30 to $72 \mathrm{~mL}$, which is $239 \%$ of the original volume. In contrast, the whole hen egg increased in volume from 30 to $88 \mathrm{~mL}$, which is $292 \%$ of the original volume. Since the volume change was larger in the hen egg, the emu whip appeared heavier. Similar results were obtained with the albumen. Since the emu egg yolk did not increase in volume when it was whipped, we diluted the egg yolk of both species with an equal volume of distilled water. The volume of the diluted emu egg yolk roughly doubled, while the volume of the hen egg yolk increased to $267 \%$. Next, we examined the syneresis rate of the whip and found more obvious differences. As shown in Fig. 1a, the whip of the whole hen egg was not as stable as the whip of the emu egg. Liquid rapidly increased in the hen egg fraction, while the whip of the emu egg did not exhibit syneresis until $40 \mathrm{~min}$, and then syneresis slowly started. Though the syneresis rate of albumen for the two species showed a similar curve (Fig. 1b), the emu whip drained more slowly. This characteristic of the emu egg is a great advantage for food production processes where meringue is used. In the case of the yolk, we compared the whip of diluted yolk and again observed a slower syneresis in the emu egg yolk (Fig. 1c). These differences are presumably derived from differences in composing proteins. The whipping property of hen egg albumen has been studied and several protein components, such as globulin and ovomucin, are known to be involved (MacDonnell et al., 1954). The protein composition of emu egg albumen will thus be essential for further analysis.

Table 3. Volume change of raw egg by whipping ( $\%$ of original volume).

\begin{tabular}{cccc} 
& Whole & Albumen & 1/2 Diluted yolk \\
\hline Emu & $239 \pm 9$ & $230 \pm 4$ & $227 \pm 30$ \\
Hen & $292 \pm 2$ & $278 \pm 7$ & $267 \pm 21$ \\
\hline
\end{tabular}

Values are expressed as mean $\pm \mathrm{SD}(\mathrm{n}=2)$. 

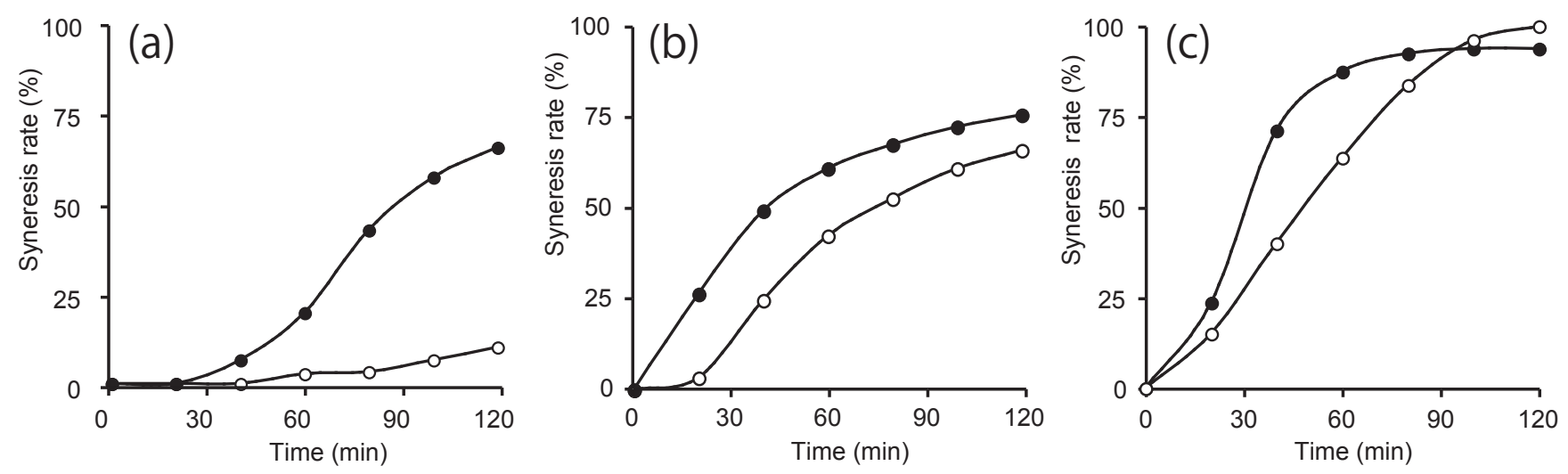

Fig. 1. Syneresis rate of each egg fraction after whipping.

Time-dependent syneresis of whip of whole egg (a), albumen (b), and diluted yolk (c) are shown. Syneresis rate (y axis) was expressed as $\mathrm{Y}=$ regenerated liquid volume/original liquid volume $\mathrm{x} 100$. Open circles correspond to emu, closed circles to hen.

The above experiments were conducted with fresh eggs. We next performed foaming experiments using frozen eggs and compared the volume change with that of fresh eggs, since frozen liquid eggs are commonly used in the food industry. Fresh egg samples were frozen at $-30^{\circ} \mathrm{C}$ overnight and thawed under water before use. As shown in Fig. 2a, freezing treatment affected the whipping property of whole eggs. In hen whole egg, the volume after whipping and freezing a $30-\mathrm{mL}$ sample decreased from $88.5 \mathrm{~mL}$ ( $295 \%$ of the original volume) to $70 \mathrm{~mL}(233 \%)$, whereas the foam volume of emu whole egg decreased from $74 \mathrm{~mL}(246 \%)$ to 52 $\mathrm{mL}(173 \%)$. Freezing caused the emu whole egg to become irreversibly gelatinized, possibly accounting for the larger decrease in foaming capacity in emu eggs. Compared to whole eggs, albumen retained greater foaming capacity after freezing (Fig. 2b). Hen egg yolk is known to denature when it is frozen. Emu egg yolk also denatured by freezing (data not shown), thus we did not examine the foaming capacity of yolks after freezing.

Heat induced coagulation and rheological analysis To examine the heat denaturation of eggs, we used a rapid visco analyzer (RVA). RVA is generally used in studies on starches (Goesaert et al., 2008), but other applications, such as in the experimental manufacture of processed cheese (Kappoor et al., 2004), have also been reported. We first examined changes in the viscosity of hen whole eggs during temperature changes, as illustrated in Fig. 3a, to see whether RVA could be applied to studies on egg coagulation. As a result, at this temperature range, denaturation did not start until the final incubation period (Fig. 3b). However, when a higher temperature was programmed, viscosity began to rise more quickly. Denaturation at lower temperatures is thus slower and requires more time. We concluded that the viscosity curve reflects the temperature, and viscosity could therefore be used as a parameter of coagulation. It should be noted that the readings became inaccurate above $3000 \mathrm{cP}$ when analyzing whole egg, because the sample coagulated on the stirring blades and the blades spun in a stress-reduced manner. Next, we compared the coagulation profiles of emu whole egg with those of hen whole egg at a temperature range of $70^{\circ} \mathrm{C}$ to $74^{\circ} \mathrm{C}$. As shown in Fig. 3c, emu egg was more sensitive to heat than hen egg. Emu egg began to coagulate at $70^{\circ} \mathrm{C}$, whereas the viscosity of hen egg did not increase at $70^{\circ} \mathrm{C}$. The difference was obvious at $73^{\circ} \mathrm{C}$, at which point the viscosity of emu egg increased sharply; over twice as much compared to hen egg. At $74^{\circ} \mathrm{C}$, hen egg also became viscous, but emu egg showed a more rapid and drastic change. Both hen and emu eggs stuck to the blades, making it impossible to reliably read viscosity above $74^{\circ} \mathrm{C}$, although complete protein denaturation may not occur above this temperature. RVA was also used to analyze the yolk (Fig. 3d). The temperature range in this analysis was $65^{\circ} \mathrm{C}$ to $70^{\circ} \mathrm{C}$, because yolks are more heat sensitive than whole egg samples. The difference between the eggs of the two species was small, with both starting to coagulate at the same temperature.
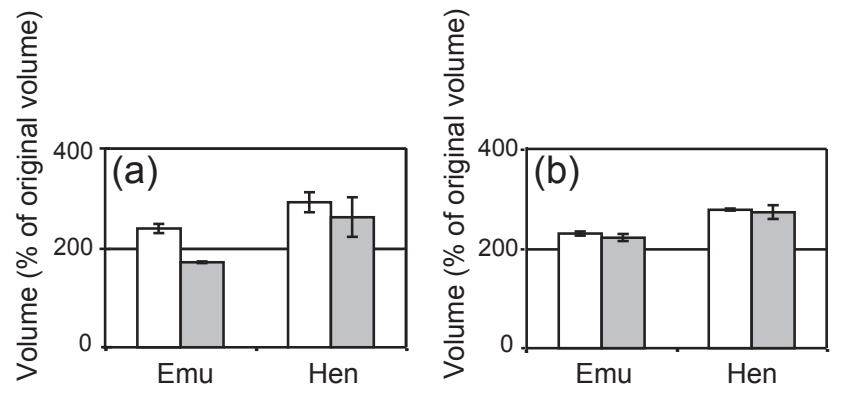

Fig. 2. Whipping capacity before and after freezing.

(a) Volume increase of fresh whole egg (open bar) and thawed frozen egg (shaded bar) by whipping was determined. Y axis expresses foam volume after whipping/original liquid volume x 100. Error bar expresses standard deviation. (b) Same experiment as (a) but albumen was used. 

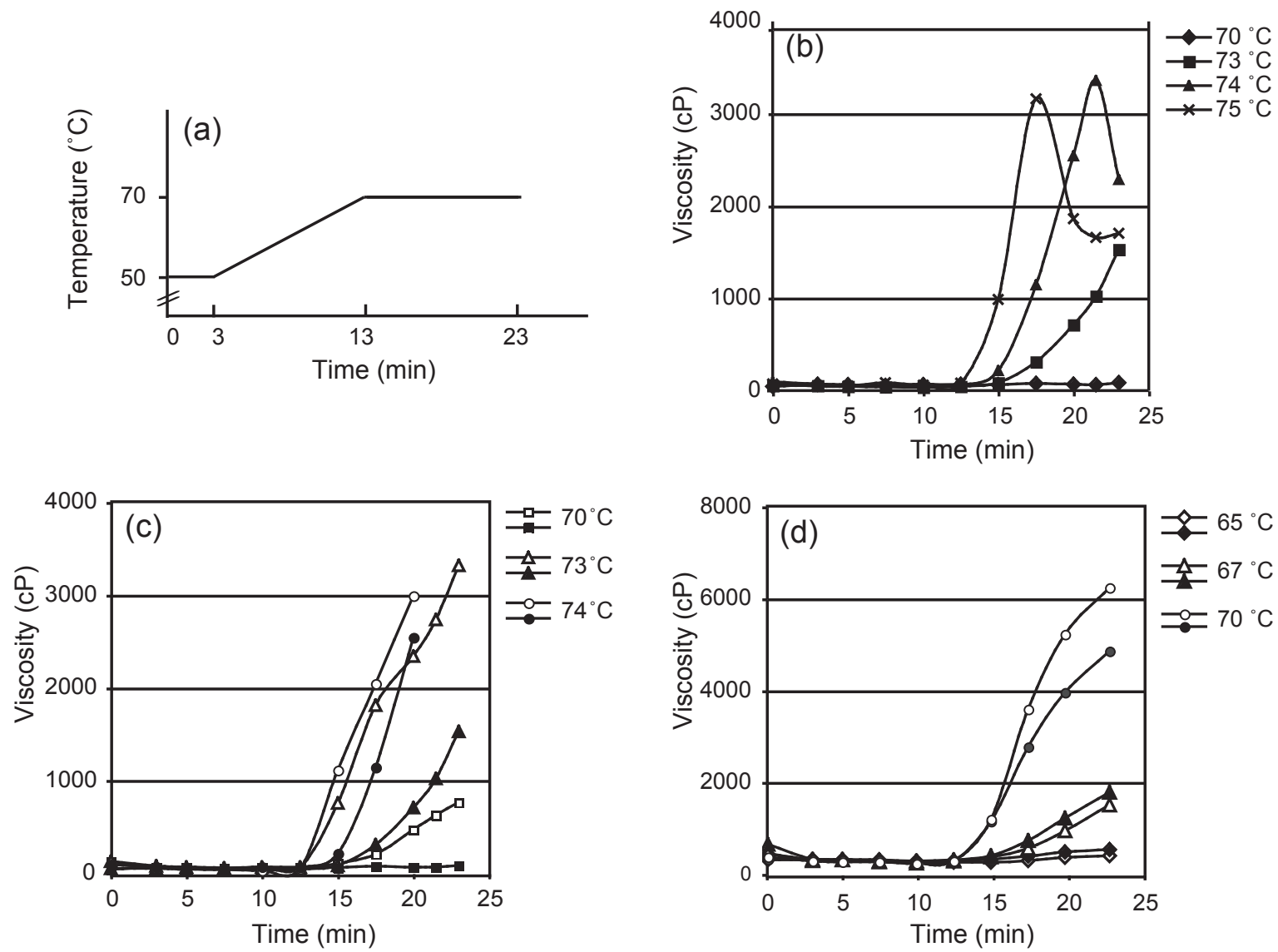

Fig. 3. Rapid viscogram patterns of heat-induced denaturation of egg.

Heat induced viscosity change was examined using RVA. Closed circles correspond to hen. Open circles correspond to emu. The temperature-shift program was as follows: pre-incubation at $50^{\circ} \mathrm{C}$ for $3 \mathrm{~min}$, temperature up-shift in 10 min from $50^{\circ} \mathrm{C}$ to the indicated temperature followed by further incubation for $10 \mathrm{~min}$. A temperature program at $70^{\circ} \mathrm{C}$ is illustrated in (a) as an example. Hen whole egg as control (b), comparison of whole egg samples (c) and yolk (d) between hen and emu were performed.

Table 4. Rheological and color analysis of boiled egg.

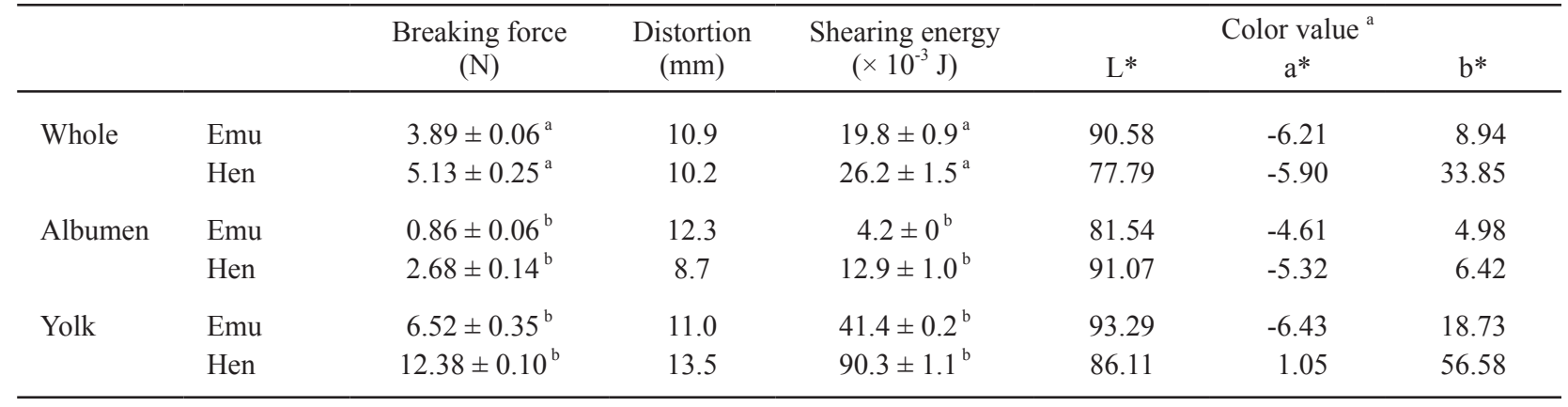

${ }^{a}$ Values are expressed as mean $\pm \operatorname{SD}(n=3)$. ${ }^{b}$ Values are expressed as mean $\pm \operatorname{SD}(n=2)$.

However, at $70^{\circ} \mathrm{C}$, the highest temperature examined, emu egg yolk showed higher viscosity than hen egg yolk. We concluded that emu egg was basically more heat sensitive than hen egg, as it started to coagulate at a lower temperature and had a higher viscosity at the same temperature compared to hen egg. RVA could not be used to analyze the albumen, because the albumen did not denature uniformly, resulting in unsteady and inaccurate readings.

Since RVA was not suitable in analyzing highly coagulat- ed samples, another method was required in order to understand properties after coagulation was complete. We therefore prepared boiled eggs in a casing tube and used a rheometer to examine their firmness. To avoid texture differences caused by boiling, an optimum condition was established with hen egg. The emu egg albumen became an extremely weak gel (Table 4) that could be sheared by one-third of the force required to break hen egg albumen. Distortion prior to the break was larger in emu egg albumen than it was in hen 
egg albumen, suggesting higher elasticity in the gel of emu egg albumen. The smaller force required for breaking also reveals the softness of the gels. The characteristic softness of emu albumen gel might be the result of the albumen's unique protein composition (Robert et al., 1960). Ovalbumin is the most abundant protein in hen egg albumen, as the $43-\mathrm{kDa}$ band is readily detected in SDS-PAGE analysis. Emu egg albumen, on the other hand, did not show a major band at 43 $\mathrm{kDa}$ (Fig. 4). This difference suggests that the ovalbumin of emu egg was either post-translationally modified or replaced by another protein with a similar biological function. Since most egg proteins are post-translationally modified, such as in phosphorylation or glycosylation, the former hypothesis is more plausible. Ovotransferrin, the second major protein in hen egg albumen, migrates as a $78-\mathrm{kDa}$ band. The same molecular-sized band was detected in emu egg albumen. Lysozyme was not detected in emu egg albumen as previously reported (Feeney et al., 1960). It is possible that the expression of anti-bacterial proteins is not necessary in emu egg, which is covered with a thick shell. In the case of the ostrich, whose egg also has a thick shell, the lysozyme-like band was detected in one case (Mineki et al., 1993) but not in another (Yokohama et al., 2009). Thus, quantities of lysozyme seem to vary, suggesting that emu eggs do not necessarily lack lysozymes. Emu egg albumen also contained a major protein of high molecular weight, which is still under investigation. It is most likely that differences in composing proteins and their patterns of modification might account for the differences in texture, whipping property, and viscosity of emu egg albumen. A comparison of both yolks revealed that the emu egg gel was approximately half as firm as the hen egg gel but that elasticity was greater in the hen egg gel. As a whole egg, the difference between the two species was relatively small, but emu egg was shown to be softer than hen egg. This result was striking, because yolk increases firmness and emu egg has a larger yolk/albumen ratio than does hen egg. When we mixed and boiled equal volumes of hen egg yolk and albumen to approximate whole emu egg composition, the boiled mixture was firmer than the boiled natural hen whole egg mixture (data not shown). Notably, emu whole egg is softer than hen whole egg in spite of emu egg's large yolk. We thus anticipated that using emu eggs instead of hen eggs in processed food might make foods softer.

Color value Emu egg had a lemon-yellow yolk, which is similar to the color of hen egg yolk. The color change during processing, however, was significant. When the yolk was mixed with the albumen, emu whole egg showed a pink beige color. Heat denaturation caused the yolk to become paler, almost like hen albumen in color. To reveal the difference, we compared the sliced surface color of boiled eggs

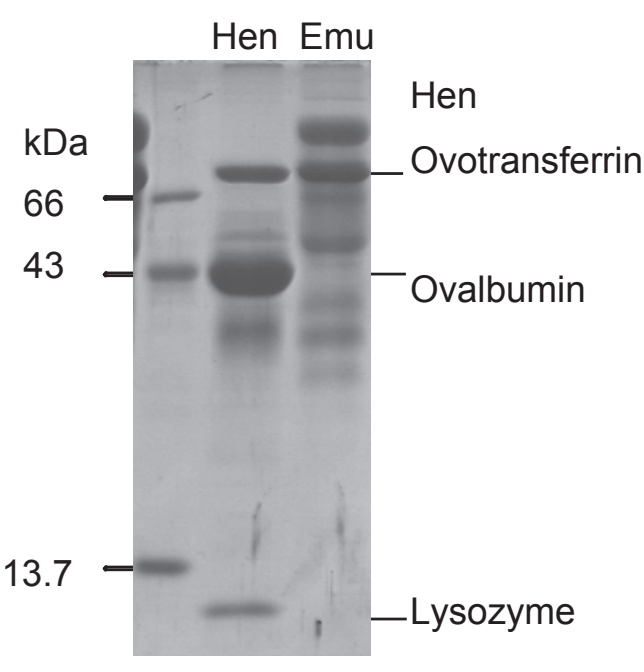

Fig. 4. SDS-PAGE analysis of albumen proteins.

Albumen fraction from each raw egg was 10 times diluted with PBS, and $1 \mu \mathrm{l}$ was subjected to a SDS-polyacrylamide gel of $12.5 \%$. Samples were analyzed by electrophoresis followed by staining with Coomassie brilliant blue. Molecular markers are shown on the left. Known protein bands in hen albumen are shown on the right.

that had been prepared in a casing tube as in the above experiment. As shown in Table 4, the difference of $\mathrm{L}^{*}$ values between the two species was most significant in whole egg. As mentioned, the $\mathrm{L}^{*}, \mathrm{a}^{*}$ and $\mathrm{b}^{*}$ values of the surface of boiled emu whole egg are more similar to those of hen egg albumen than to whole hen egg. Emu whole egg had a higher $\mathrm{L}^{*}$ value, which indicates brighter whiteness. The $\mathrm{L}^{*}$ value is often negatively correlated with ash content (Oliver et al., 1993), which is contradictory to the result of proximate composition (Table 1). Therefore, there might be other factors that make the color of emu egg paler when it is boiled. The difference in the $\mathrm{L}^{*}$ values of the yolk was relatively small, though the $a^{*}$ and $b^{*}$ values were significantly different between emu and hen egg yolks. Emu egg yolk had lower a* value, which expresses a less intense red. Emu egg yolk also had a lower $b^{*}$ value, meaning paler yellowness. The lower $b^{*}$ value strongly influenced the low $b^{*}$ value of whole egg. The paleness of emu egg strongly affects the color of processed foods (described below). Color difference, however, is not an important quality because it can be adjusted during processing. Boiled emu albumen looked more translucent than boiled hen albumen; a lower $\mathrm{L}^{*}$ value was gained for emu albumen since more light penetrated through it than boiled hen albumen. Hatanaka et al. (2009) reported that hen albumen forms a more transparent, weaker gel at an alkaline $\mathrm{pH}$. In our study, emu egg albumen had an alkaline $\mathrm{pH}$ of 9.2, which is within the normal $\mathrm{pH}$ range of hen albumen one day after the egg is laid (Rocculia et al., 2008). The pink beige color was reproduced by mixing equal volumes of emu yolk 
Table 5. Expansive properties and color values of cakes.

\begin{tabular}{lccccc}
\hline & $\begin{array}{c}\text { Specific volume } \\
(\mathrm{mL} / \mathrm{g})\end{array}$ & $\begin{array}{c}\text { Max. height } \\
(\mathrm{cm})\end{array}$ & $\mathrm{L}^{*}$ & $\begin{array}{c}\text { Color value } \\
\mathrm{a}^{*}\end{array}$ & $\mathrm{~b}^{*}$ \\
\hline $\mathrm{Emu}$ & $1.48 \pm 0.01^{\mathrm{a}}$ & 4.2 & 74.5 & -5.4 & 19.7 \\
$\mathrm{Hen}$ & $1.31 \pm 0.01^{\mathrm{a}}$ & 4.5 & 75.6 & -6.1 & 34.3 \\
\hline${ }^{\mathrm{a}}$ Values are expressed as mean \pm SD $(\mathrm{n}=2)$. & & & \\
${ }^{\mathrm{b}}$ Values are the mean of readings of three loci. & & &
\end{tabular}

and hen albumen (data not shown), suggesting that the albumen of emu eggs is not actively involved in the production of the pink beige color of whole egg.

Applications of emu eggs Finally, we examined the influence of the above properties on processed food. To study the expansive property of batter using frozen whole eggs, butter cake was employed as the simplest approach: the eggs do not need to be whipped, and expansion is solely due to the eggs. We first measured the specific volume of the cakes. The cake made with emu eggs had a larger volume/weight value, although the maximum cake height was lower than the height of the cake made with hen eggs (Table 5). This discrepancy is explained by the difference in the shape of the cake. The cake made with emu eggs expanded evenly in the vertical direction, while the center of the cake made with hen eggs expanded more than other areas. As a result, a vertical slice of the cake made with hen eggs had an inverted V-shape, whereas the top of the cake made with emu eggs was relatively flat (Fig. 5a).

Next, we examined the physical properties of the cakes. Rheological examination revealed that the force to dent a cake was expressed as a linear slope for the initial $5.0 \mathrm{~mm}$ of the depression. We therefore compared the force required to press a cake $5.0 \mathrm{~mm}$ deep (Fig. $5 \mathrm{~b}$ ). The result indicated that a control cake made with hen eggs was about 1.7 times firmer than the cake made with emu eggs. According to a sensory analysis, 10 out of 11 panelists judged that the cake made with emu eggs was softer than the cake made with hen eggs; this result was statistically significant $(p<0.05)$. Therefore emu eggs prove to provide significant softness to cake.

Yolk color markedly influences cake color. The sliced surface of a cake made with emu eggs looked extremely pale (Table 5). Yellowness, expressed by the $\mathrm{b}^{*}$ value, is noticeably low in cakes made with emu eggs.

Emu eggs also had a disadvantage. Cake made with emu eggs was rather crumbly, whereas cake made with hen eggs was more intact (Fig. 5a). This property suggests it would be difficult to use emu eggs instead of hen eggs for foods that require integrity and adhesiveness. Overall, we believe that emu egg is a useful new foodstuff that can be used to adjust the softness of baked products. (a)

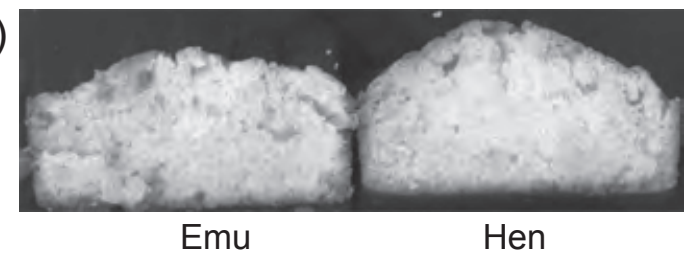

(b)

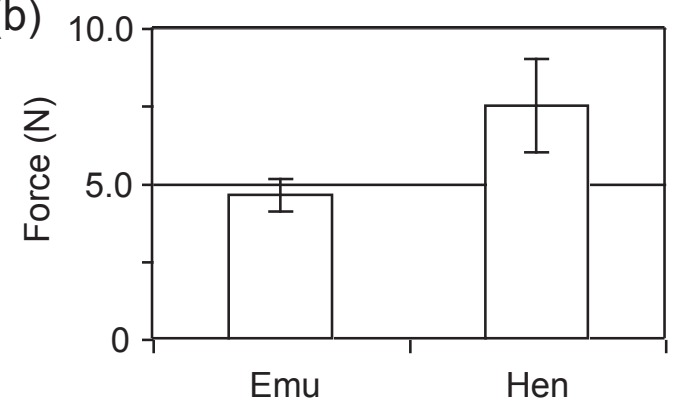

Fig. 5. Property of cakes made of frozen emu or hen whole egg. Vertical slices ( $2 \mathrm{~cm}$ thick) were cut out and the surface was scanned (a). The slices were pressed by rheometer and the force required to dent the cake $5 \mathrm{~mm}$ deep was measured (b). Error bar represents standard deviation in triplicate measurements.

Acknowledgements We thank Tokyo Nodai Bio-industry for supplying emu eggs. We thank Dr. Takeshi Nagai for reviewing this manuscript, and Dr. Yozo Nakazawa for his technical advice.

\section{References}

Angalet, S.A. and Harms, R.H. (1976). Quality and flavor of broilers egg yolk color and egg flavor. Poult. Sci., 55, 1219-1225.

Feeney, R.E., Anderson, J.S., Azari, P.R., Bennett, N., and Rhodes, M.B. (1960). The comparative biochemistry of avian albumen proteins. J. Biol. Chem., 235, 2307-2311.

Goesaert, H., Leman, P., and Delcour, J.A. (2008). Model approach to starch functionality in bread making. J. Agric. Food Chem., 56, 6423-6431.

Hamada, M. and Inamasu, Y. (1983). Influence of temperature and water content on the viscoelasticity of kamaboko. Bull. Jpn. Soc. Sci. Fish, 49, 1897-1902.

Hatanaka, Y., Yamauchi, A., Kobayashi, O., and Muro, T. (2009). Electron microscopic analysis of the effects of tea extract on strength improvement of egg white gels. Food Sci. Technol. Res., 
15, 5-10

Herber-McNeill, S.M. and Van Elswyk, M.E. (1998). Dietary marine algae maintains egg consumer acceptability while enhancing yolk color. Poult. Sci., 77, 493-496.

Kapoor, R., Lehtola, P., and Metzger, L.E. (2004). Comparison of pilot-scale and rapid visco analyzer process cheese manufacture. J. Dairy Sci., 87, 2813-2821.

Koga, K. (1969). Studies on the emu albumen proteins: (I) Electrophoresis, CM-cellulose chromatography and gradient extraction with salt on the whole white. Memoirs of the Faculty of Agriculture, Kagoshima University, 7, 35-46.

Laemmli, U.K. (1970). Cleavage of structural proteins during the assembly of the head of bacteriophage T4. Nature, 227, 680-685.

MacDonnell, L.R., Feeney, R.E., Hanson, H.L., Campbell, A., and Sugihara, T.F. (1954). The functional properties of the egg white proteins. Food Technol., February, 49-53.

Mext, Japan (2005). Standard tables of food composition in Japan. 5 th revised and enlarged ed. National Printing Bureau (in Japanese).

Mineki, M., Tanahashi, N., and Shidara, H. (2003). Physical and chemical properties of ostrich egg (Struthio camelus domesticus): Comparison with white leghorn hen egg. Nippon Shokuhin Kagaku Kogaku Kaishi, 50, 266-271 (in Japanese).
Oliver, J.R., Blakeney, A.B., and Allen, H.M. (1993). The colour of flour streams as related to ash and pigment contents. J. Cereal Sci., 17, 169-182.

Rabouille, C., Aon, M.A., and Thomas, D. (1989). Interactions involved in ovomucin gel-forming properties: a rheologicalbiochemical approach. Arch. Biochem. Biophys., 270, 495-503.

Robinson, D.S. and Monsey, J.B. (1972). Changes in the composition of ovomucin during liquefaction of thick egg white. J. Sci. Food Agric., 23, 29-38.

Rocculia, P., Tylewicza, U., Pękosławskab, A., Romania, S., Sirria, F., Siracusac, V., and Dalla Rosaa, M. (2009) MAP storage of shell hen eggs, Part 1: Effect on physico-chemical characteristics of the fresh product. LWT - Food Sci. Technol., 42, 758-762.

Sales, J., Poggenpoel, D.G., and Cilliers, S.C. (1996). Comparative physical and nutritive characteristics of ostrich eggs. World Poult. Sci. J., 52, 45-52.

Yang, S.C., and Baldwin, R.E. (1995). Functional properties of egg in foods. In "Egg science and technology" ed. by Stadelman, W.J., and Cptterill, O.J. 4th edn. Food Product Press, pp. 405-464.

Yokohama, M., Sayama, Y., and Ogawa, H. (2009) Comparison of SDS-polyacrylamide electrophoresis pattern among albumen components in emu and other birds. J. Electrophoresis, 53, pp. 41-42 (in Japanese). 